\title{
IN SITU LATERAL LOAD TESTS ON INSTRUMENTED BORED PILES IN LOESSIAL SOILS
}

Sebastian DRĂGHICI - PhD student, Technical University of Civil Engineering Bucharest, Faculty of Hydrotechnics, e-mail: draghici_sebastian@yahoo.com

Anatolie MARCU - Professor, PhD, Technical University of Civil Engineering Bucharest, Soil Mechanics and Foundations Engineering Department, email: an.marcu@yahoo.com

\begin{abstract}
The aim of the paper is to provide some aspects regarding the behaviour of laterally loaded piles in loessial soils, by presenting and analysing the results of several in situ tests on large diameter bored piles in this type of soil. The major feature of loess is that it exhibits a massive decline of its strength and stiffness parameters when it comes into contact with water, leading to the collapse of its structure even under self-weight and creating difficult conditions for foundations. The load tests were performed both in natural moisture content loess and also in saturated loess. The results obtained by means of instrumentation are back-analysed using current analytical methods and also by finite element method using a numerical model in the geotechnical computation software Plaxis 3D.
\end{abstract}

Keywords: laterally loaded piles, loessoil soils, Finite Element Method

\section{Introduction}

The increase of high-rise buildings and implicitly the amplification of the forces transmitted to the foundation systems require in-depth studies of deep foundation behaviour under lateral loads. Considering that in many cases it is necessary to adapt the foundation to difficult ground conditions, the aspects regarding the foundation elements behaviour are even more important.

Water sensitive soils (loess and loessial soils) are spread over the world on large areas. The main characteristic of this type of soil is their sensitivity to water, manifested by a significant loss of its strength and stiffness parameters. This feature frames the water sensitive soils into difficult foundation ground category.

This paper presents the results of several in-situ natural scale load tests on laterally loaded bored piles embedded partially in water sensitive soils. The acquired data is analysed through analytical and numerical methods, with the scope of providing a studying the influence of the softened layers upon the behaviour of the pile.

Figure 1 shows a sample of natural moisture content loess to which a small amount of water was added without applying any load, in order to highlight its sensitivity to water.
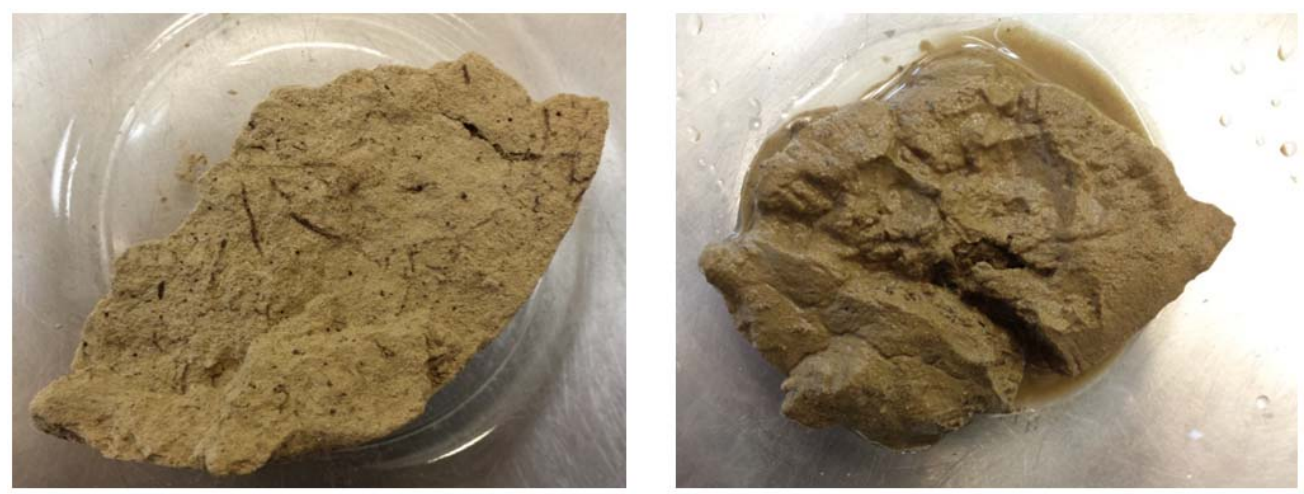

Fig. 1 - Sample of loess before and after the addition of water - collapse of structure 


\section{Current practice for analysis of laterally loaded piles}

For the analysis of piles under lateral loads, several methods have been developed along the years, being differentiated mainly by the behaviour assumed for the surrounding ground and for the pile material (Reese and Van Impe, 2001) [1].

Pile and ground with elastic behaviour - Fig. 2a

Elastic pile and ground modelled through finite elements - Fig. $2 b$

Rigid pile and elastic-plastic ground - Fig. 2c

a)

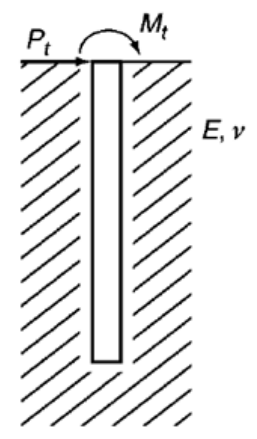

b)

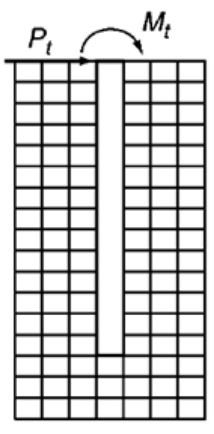

c)

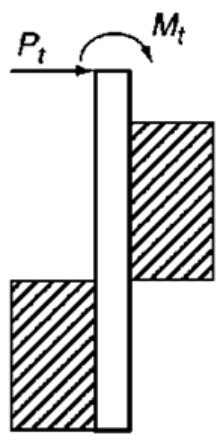

Fig. 2 - Analysis models for laterally loaded piles (after Reese and Van Impe, 2001)

Figure 2a depicts a pile with elastic behaviour within an elastic soil, defined by parameters $\mathrm{E}$ and v. Using the beam on elastic foundation theory, developed by Hetenyi (1946) [2], Terzaghi (1955) [3] suggested a series of values for the so-called soil reaction coefficient, to determine the maximum bending moment and displacement of the pile.

Figure $2 \mathrm{~b}$ is a representation of the pile into a discrete medium using finite elements. The analysis could be plane-strain (2D) or three-dimensional (3D) and may include the non-linearity of the soil behaviour. This method could offer a complete solution for the study, depending on the complexity of the analysis, yet it is also the most time-consuming and requires a multitude of input parameters as well as modelling the interface between pile and soil.

Figure 2c refers to the model developed by Broms (1964) [4], which considers the pile to be rigid and the soil pressure to reach the limits allowed by soil mechanics. The static equilibrium equation for the pile provides only the ultimate lateral load and allowable bending moment, while for assessing the displacements, the elastic model would be employed.

Apart from the above mentioned analytical models, semi-empirical methods can also be used to study the behaviour of laterally loaded piles. In this respect, the , $p-y$ ” curves method and „characteristic load" method (Duncan, 1994) [5] are available.
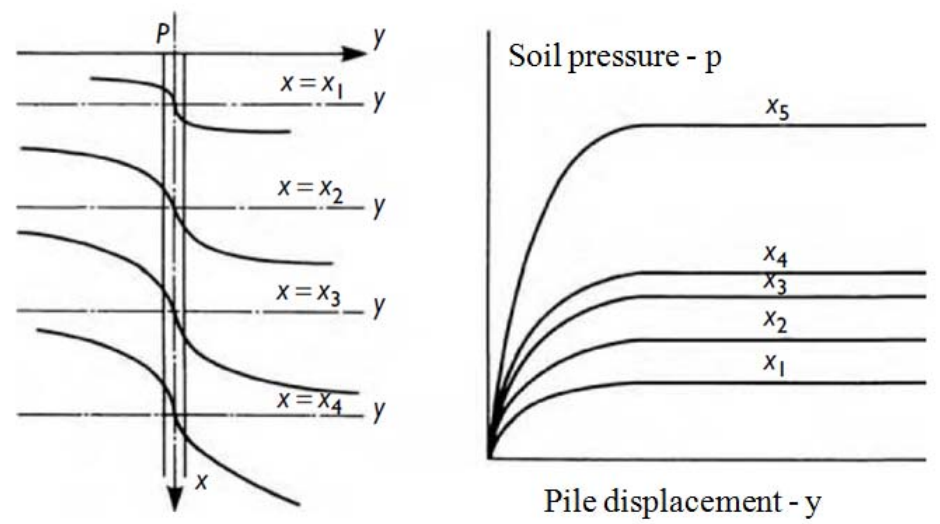

Fig. 3 - „p-y” curves for laterally loaded piles (after Matlock, 1970) [6] 


\section{Load tests description}

During the last years, in the south-east region of Romania, area with a high aeolian potential, yet with also a large spread of loessoil soils, numerous wind farms were developed, requiring deep foundations.

The wind turbines are structures mainly subjected to the wind action and therefore considerable lateral forces and bending moments are transmitted to the foundation systems consisting generally of bored piles. The equipment inside the wind turbine structures are highly sensitive to displacements and deformations, reason for which an evaluation of the deformation the foundation - structure system is necessary.

In assessing the performance of the foundation systems, static lateral load tests were performed on piles especially constructed. Thus, three lateral load tests located into three different areas are analysed. Each load test comprises two stages. The first stage is represented by the lateral loading of the piles in natural water content ground conditions, up to a certain load, followed by complete unloading. It is important to mention that the tests were performed with keeping the deformations for this stage in the elastic domain.

After completion of the first stage, the water sensitive layers were saturated with the help of water infiltration boreholes. In the second stage the piles were re-loaded up to reaching the failure criterion, meaning a displacement of the piles head larger than $10 \%$ of their diameter.

Table 1

Specifications for the test piles

\begin{tabular}{|l|c|c|c|}
\hline \multicolumn{1}{|c|}{ Property } & Test pile 1 (TP1) & Test pile 2 (TP2) & Test pile 3 (TP3) \\
\hline Diameter $(\mathrm{m})$ & 0.60 & 0.60 & 0.60 \\
\hline Active length $(\mathrm{m})$ & 26.50 & 33.70 & 16.50 \\
\hline Thickness of loess layer $(\mathrm{m})$ & 3.70 & 3.80 & 8.30 \\
\hline Static horizontal load applied $(\mathrm{kN})$ & 320 & 400 & 360 \\
\hline
\end{tabular}

In regards to the instrumentation of the piles, the displacements of the pile head were measured by two dial gauges positioned at one metre apart. Inclinometer measurements were also carried out using a special tube fixed to the rebar cage during the installation of the pile. Pairs of vibrating wire strain gauges measured the micro-strains over the cross section of the piles at various levels.

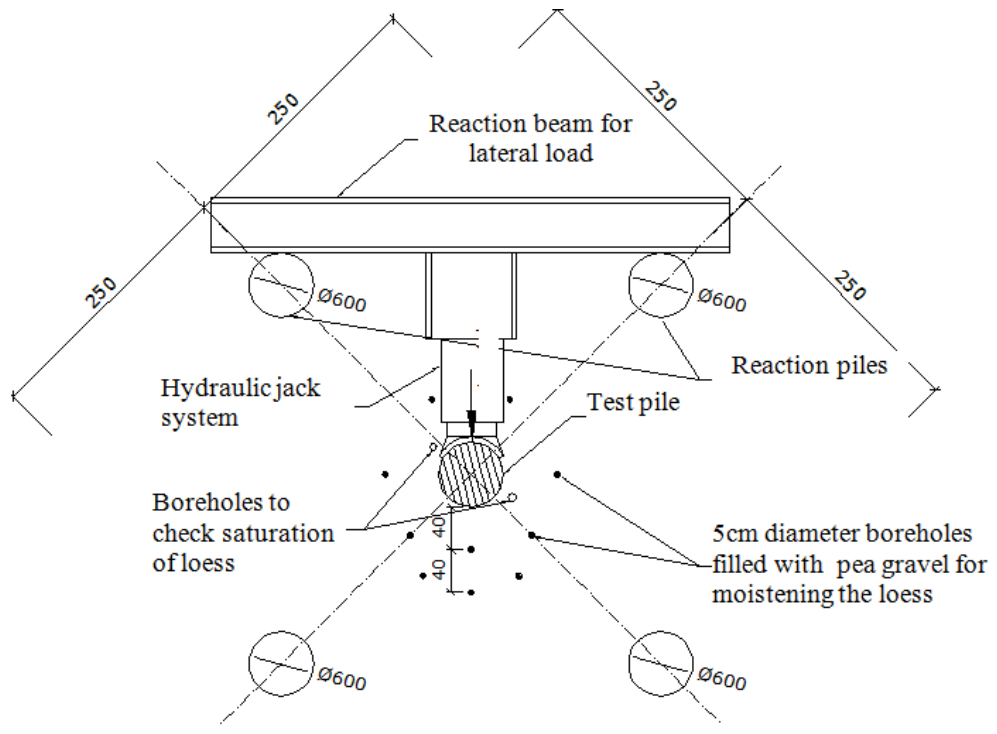

Fig. 4 - General pile layout for laterally load tests 

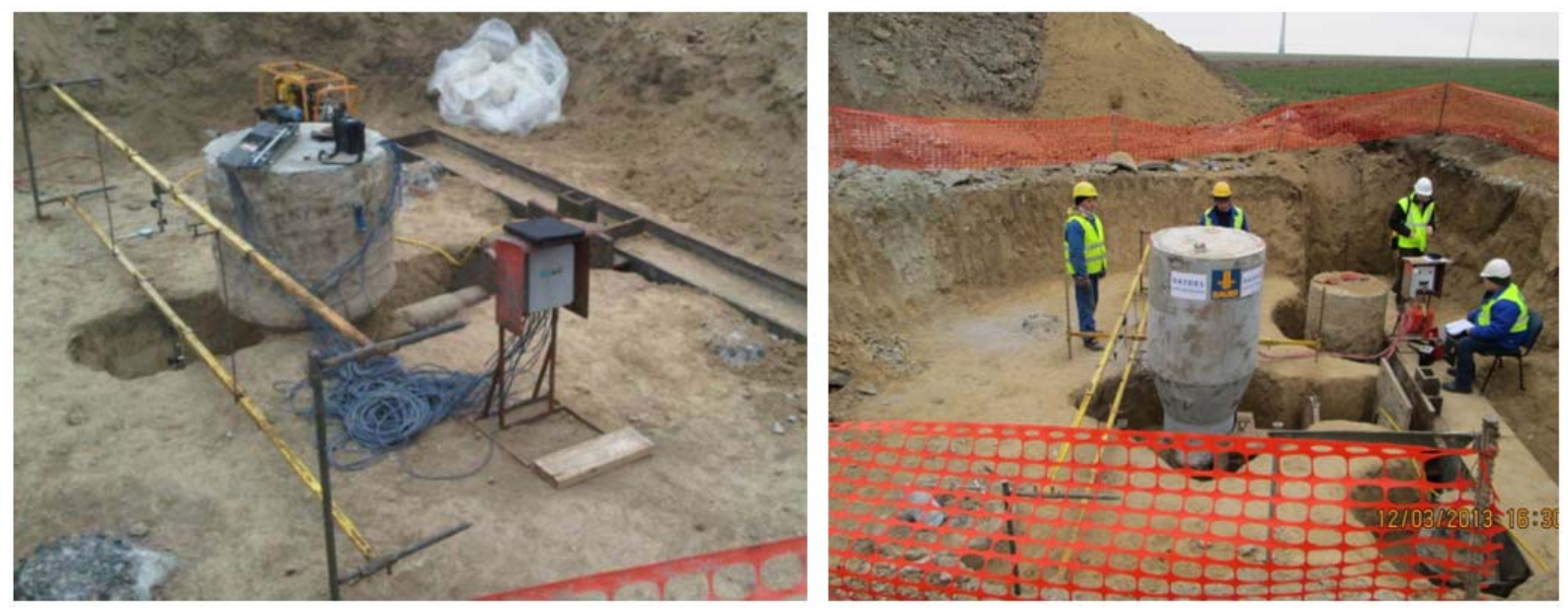

Fig. 5 - Static lateral load tests performance at TP1 and TP3 sites

After performing the lateral load test in natural water content ground conditions, water infiltration boreholes with a diameter of $50 \mathrm{~mm}$ were drilled around the test pile through the depth of the water sensitive layer. The boreholes were filled with high permeability granular material (pea gravel) to ensure the infiltration of water over full thickness of the layer. When the saturation of soil was obtained, the lateral load tests in saturated ground conditions were performed up to same load as in natural ground condition.

The geotechnical parameters for the natural state loessoil soils have been obtained through a site investigation program including boreholes on each test location and laboratory testing. The sets of parameters considered in the analysis of the load tests are presented in Table 2.

Table 2

Geotechnical parameters for loessoil soils in natural state

\begin{tabular}{|c|c|c|c|c|c|c|c|c|c|}
\hline \multirow{2}{*}{$\begin{array}{l}\text { Test } \\
\text { pile }\end{array}$} & \multicolumn{3}{|c|}{$\begin{array}{c}\text { Grain size distribution } \\
{[\%]}\end{array}$} & \multirow{2}{*}{$\begin{array}{c}\text { Unit } \\
\text { weight } \\
{\left[\mathrm{kN} / \mathrm{m}^{3}\right]}\end{array}$} & \multirow{2}{*}{$\begin{array}{l}\text { Porosityn } \\
{[\%]}\end{array}$} & \multirow{2}{*}{$\begin{array}{c}\text { Natural } \\
\text { moisture } \\
\text { content } \\
{[\%]}\end{array}$} & \multirow{2}{*}{$\begin{array}{c}\text { Consistency } \\
\text { index, } \\
\mathrm{I}_{\mathrm{c}}\end{array}$} & \multirow{2}{*}{$\begin{array}{c}\text { Cohesion } \\
\qquad[\mathrm{kPa}]\end{array}$} & \multirow{2}{*}{$\begin{array}{c}\text { Angle of } \\
\text { friction } \\
{\left[^{\circ}\right]}\end{array}$} \\
\hline & Clay & Silt & Sand & & & & & & \\
\hline $\mathrm{TP}_{1}$ & 30 & 50 & 20 & 19 & 38 & 14 & 1.29 & 44 & 30 \\
\hline $\mathrm{TP}_{2}$ & 20 & 59 & 21 & 18 & 42 & 16 & 1.14 & 13 & 26 \\
\hline $\mathrm{TP}_{3}$ & 31 & 58 & 11 & 16 & 51 & 13 & 1.30 & 6 & 33 \\
\hline
\end{tabular}

\section{Calculation models}

\subsection{NP 123:2010 standard method}

For the analysis of a single pile laterally loaded, the current code of practice suggests the use of the "beam on elastic foundation" theory, which assumes for the soil behaviour a subgrade coefficient model (independent elastic springs).

The spring property of deformation under the horizontal pressure transmitted by the pile is called "horizontal subgrade coefficient". It is depth variable and expressed by the symbol $\mathrm{E}_{\mathrm{s}}$.

The method proposed by the standard is an analytical method and the differential equilibrium is given by the following relation [7]:

$$
(E I)_{P} \frac{d^{4} y}{d z^{4}}+E_{s} y=0
$$


For a linear-elastic soil, the method is using following relations to determine the response of the laterally loaded pile:

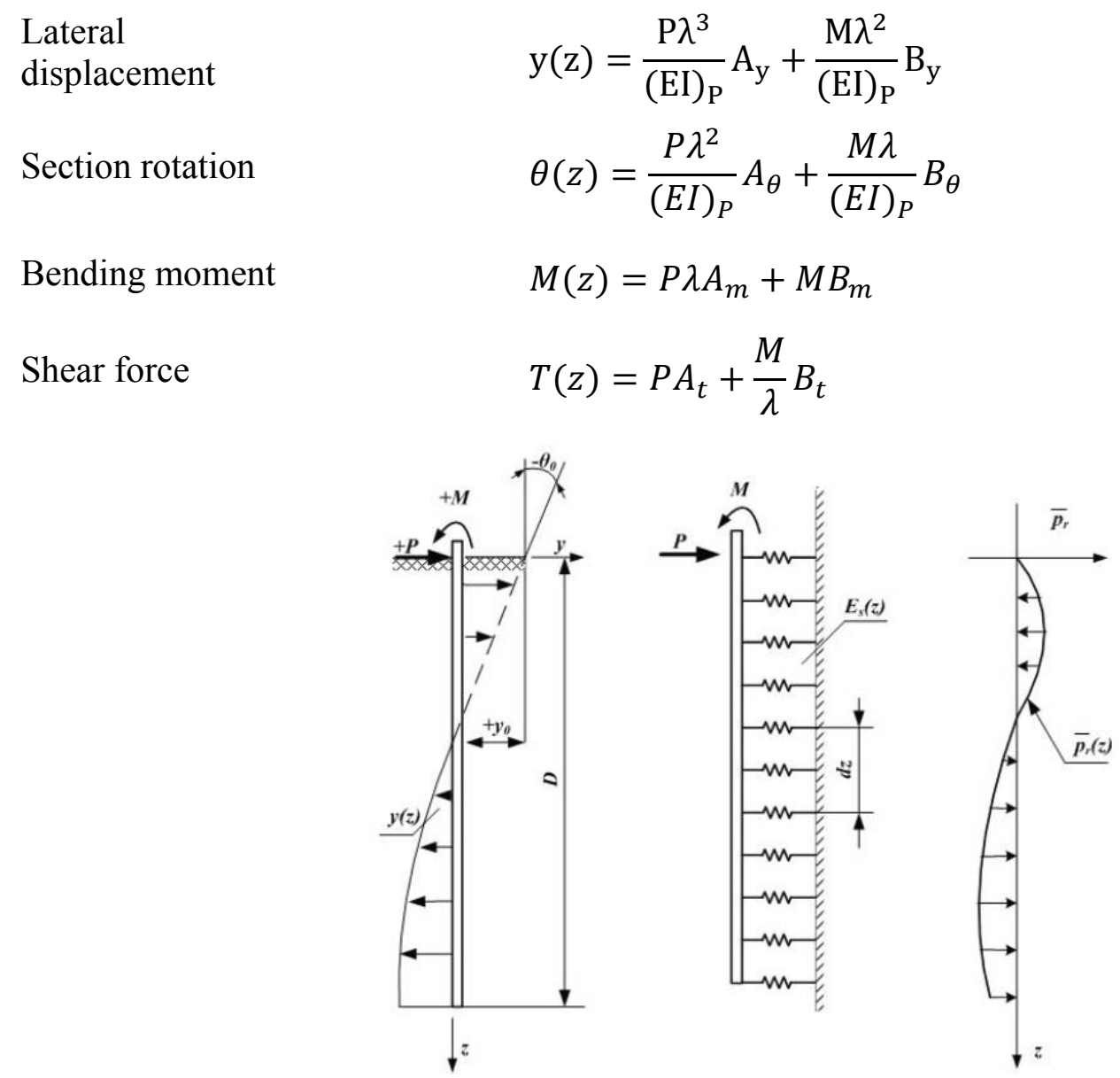

Fig. 6 - Beam on elastic foundation model (NP 123:2010) [7]

The method proposed by the code was applied for the analysis of the load tests and based on an iterative calculation process, a set of design parameters was determined.

The main variable in the calculation is the proportionality coefficient $K$, necessary for determining the subgrade reaction coefficient $\mathrm{E}_{\mathrm{s}}$. For the initial estimate, the interval recommended by the code for silty soils with a consistency index $I_{c}$ greater than unity was used. In this case, table C.1 of the aforementioned code suggests values between 4,000 and 6,000 $\mathrm{kN} / \mathrm{m}^{4}$.

Table 3

Design parameters

\begin{tabular}{|c|c|c|c|c|c|}
\hline \multirow{2}{*}{ Test pile } & Soil type & $\begin{array}{c}\text { Maximum load } \\
\text { applied } \\
{[\mathrm{kN}]}\end{array}$ & $\begin{array}{c}\text { Angle of } \\
\text { internal friction } \\
{\left[{ }^{\circ}\right]}\end{array}$ & $\begin{array}{c}\text { Active } \\
\text { width, } \mathrm{b}_{\mathrm{c}} \\
{[\mathrm{m}]}\end{array}$ & $\begin{array}{c}\text { Proportionality } \\
\text { coefficient, K } \\
{\left[\mathrm{kN} / \mathrm{m}^{4}\right]}\end{array}$ \\
\hline \multirow{3}{*}{$\mathrm{TP}_{1}$} & Natural & 320 & 30 & 0.946 & 12,000 \\
\cline { 2 - 6 } & Moistened & 360 & 20 & 0.818 & 4,000 \\
\hline \multirow{2}{*}{$\mathrm{TP}_{2}$} & Natural & 400 & 26 & 0.893 & 10,000 \\
\cline { 2 - 6 } & Moistened & 400 & 20 & 0.818 & 3,500 \\
\hline \multirow{2}{*}{$\mathrm{TP}_{3}$} & Natural & 360 & 33 & 0.990 & 3,500 \\
\cline { 2 - 6 } & Moistened & 360 & 15 & 0.761 & 1,600 \\
\hline
\end{tabular}


Following figures present the lateral displacement profile for each load test, both under natural conditions and saturated loess.

The in-situ displacement profile is obtained through inclinometer measurements, while the NP123 profile is calculated to a depth of approximately $10 \mathrm{~m}$, where the pile is assumed to be fixed under the applied lateral loads.

As a convention, throughout the text, dry loess refers to the natural water content state of the soil and moistened loess refers to the saturated state, obtained with the use of water infiltration boreholes. The in-situ measurements, included in the static load test reports [9], were made available by the company who performed all three load tests, Saidel Engineering.

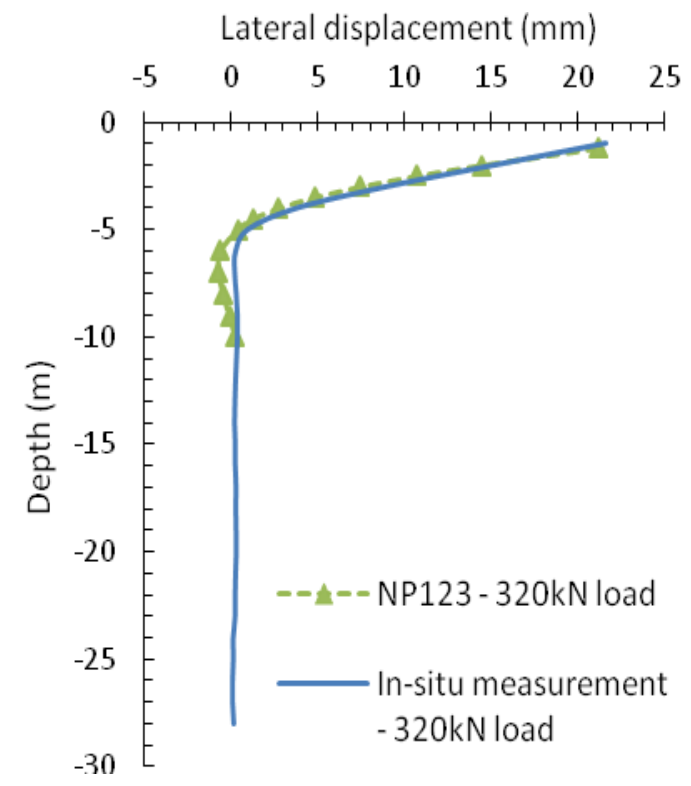

Fig. 7 - TP1 lateral displacement - dry loess

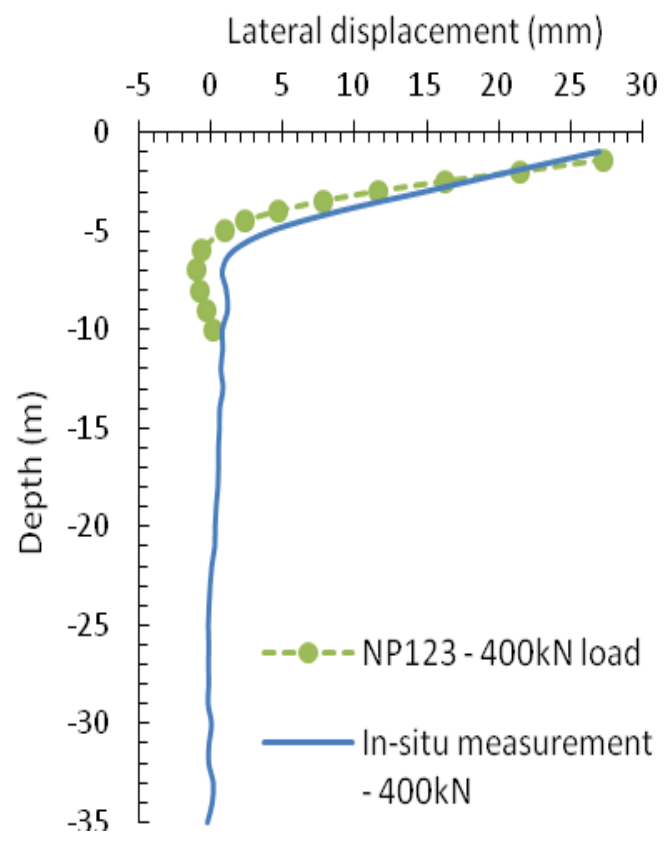

Fig. 9 - TP2 lateral displacement - dry loess

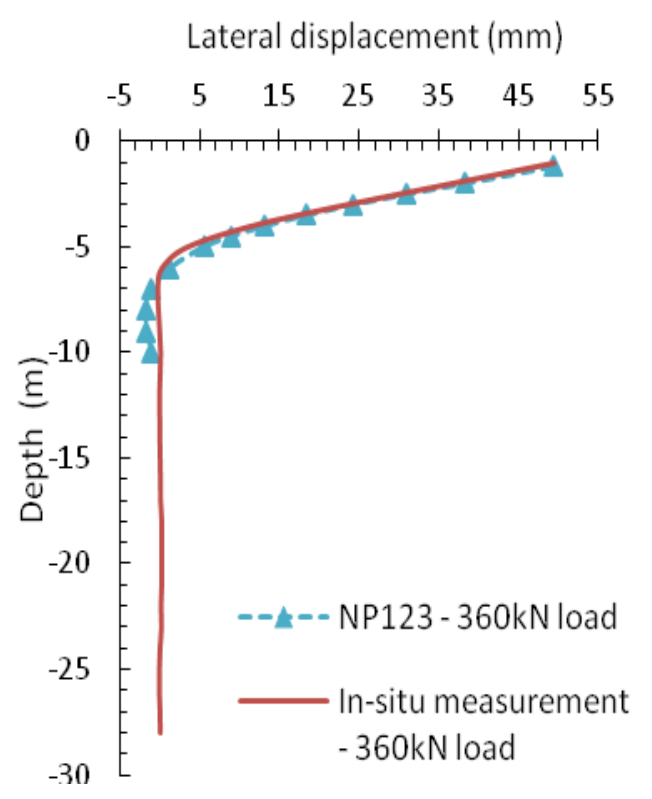

Fig. 8 - TP1 lateral displacement saturated loess

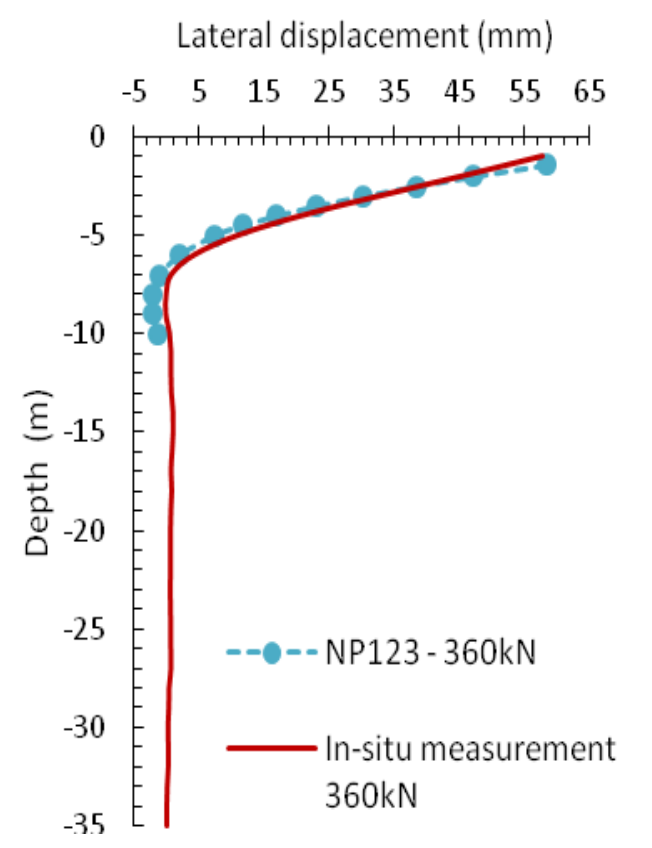

Fig. 10 - TP2 lateral displacement saturated loess 


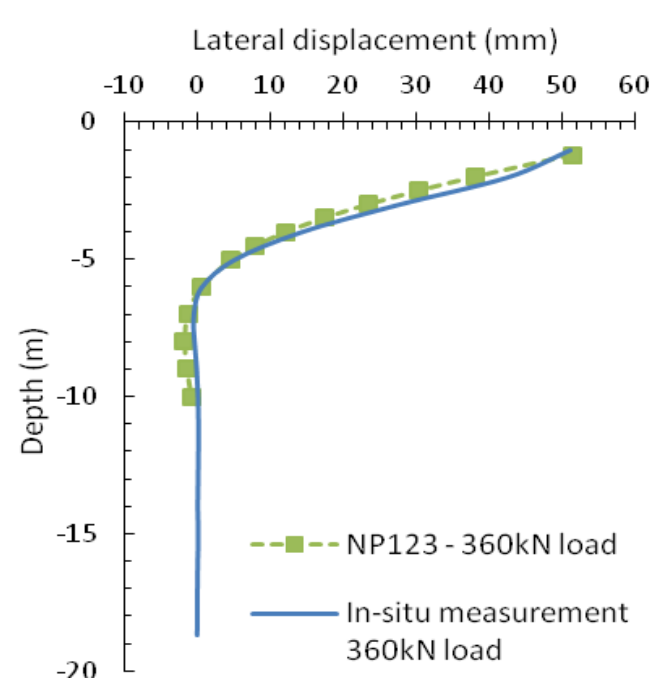

Fig. 11 - TP3 lateral displacement - dry loess

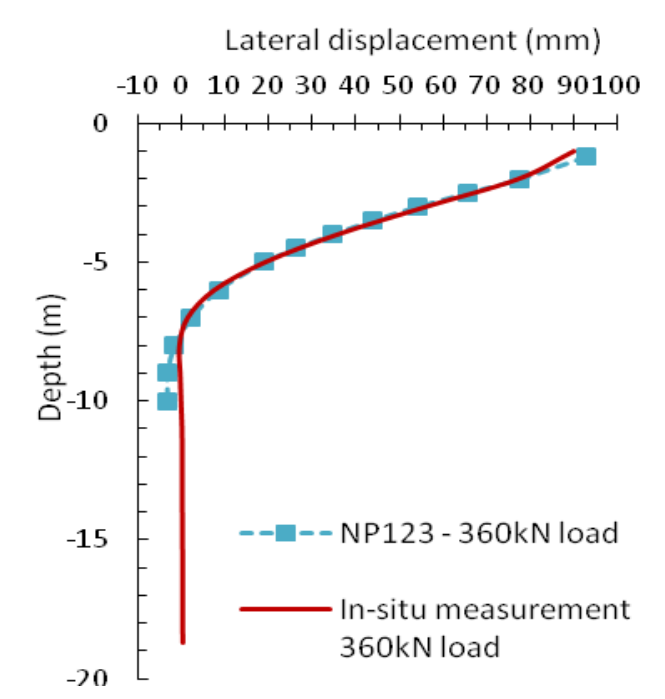

Fig. 12 - TP3 lateral displacement saturated loess

\subsection{Finite element method}

For the analysis using the numerical method, geotechnical applications specialized software Plaxis 3D [8] was considered. The aim of the analysis is to simulate the lateral load tests, by following the construction stages and determining the calibrated geotechnical parameters of the loess, both in natural state and saturated.

The numerical model follows the construction stages and the maximum load step is applied for each load test. Prior to the lateral load tests, the piles were also tested for compression loads. The compression load test required 4 reaction or anchor piles which were in place at the time of the lateral load test. Two of these four anchor piles were also used within the reaction system for the lateral load.

To simplify the numerical model, the piles used as reaction for the lateral load were not included, as their presence it is considered not to have a significant effect on the results of the load test. The reaction piles found on the load direction were included though, as it is assumed they would provide a stiffening effect of the ground in front of the test pile.

The piles were modelled using volume elements, for a more accurate simulation of their behaviour. The lateral displacement profiles were determined by using a beam type element with a very low stiffness embedded into the volume pile.

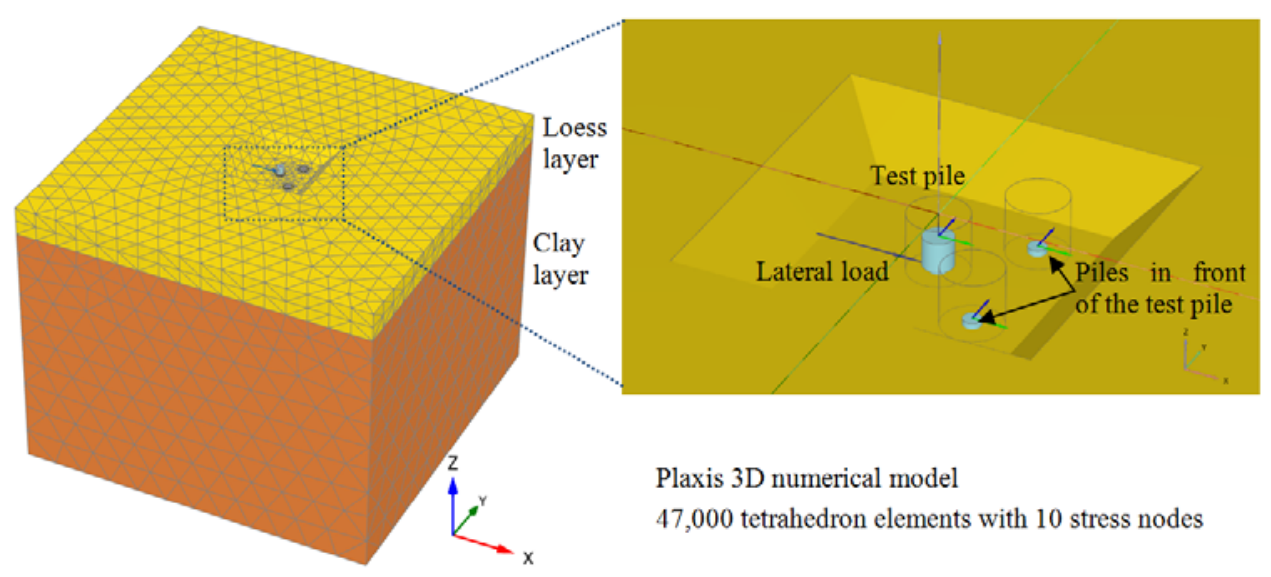

Fig. 13 - Plaxis 3D model for lateral load test 
The piles were modelled as volumes, assuming for the concrete a material with elastic behaviour, based on the large difference in stiffness between the concrete and surrounding soil.

For the behaviour of the loess and clay layer, the Mohr-Coulomb constitutive model was considered, as it is a robust model requiring a reduced set a parameters such as cohesion, angle of friction and stiffness modulus.

The FEM calculations considered as initial values for the loess stiffness the linear variation previously obtained through the analytical method (NP 123:2010). By an interative process with the scope of fitting the lateral displacement profile measured in situ and the one resulted by FEM simulation, the soil stiffness values presented in Table 4 were obtained. The stiffness modulus was also compared with the oedometer tests results included in the ground investigation report.

The contact between the piles and soil is modelled by an interface element, characterized by the parameter $\mathrm{R}_{\text {int }}$, which allows the relative displacement between pile and soil. As recommended by the software user guide, a value of 0.70 is considered to be adequate for the interface.

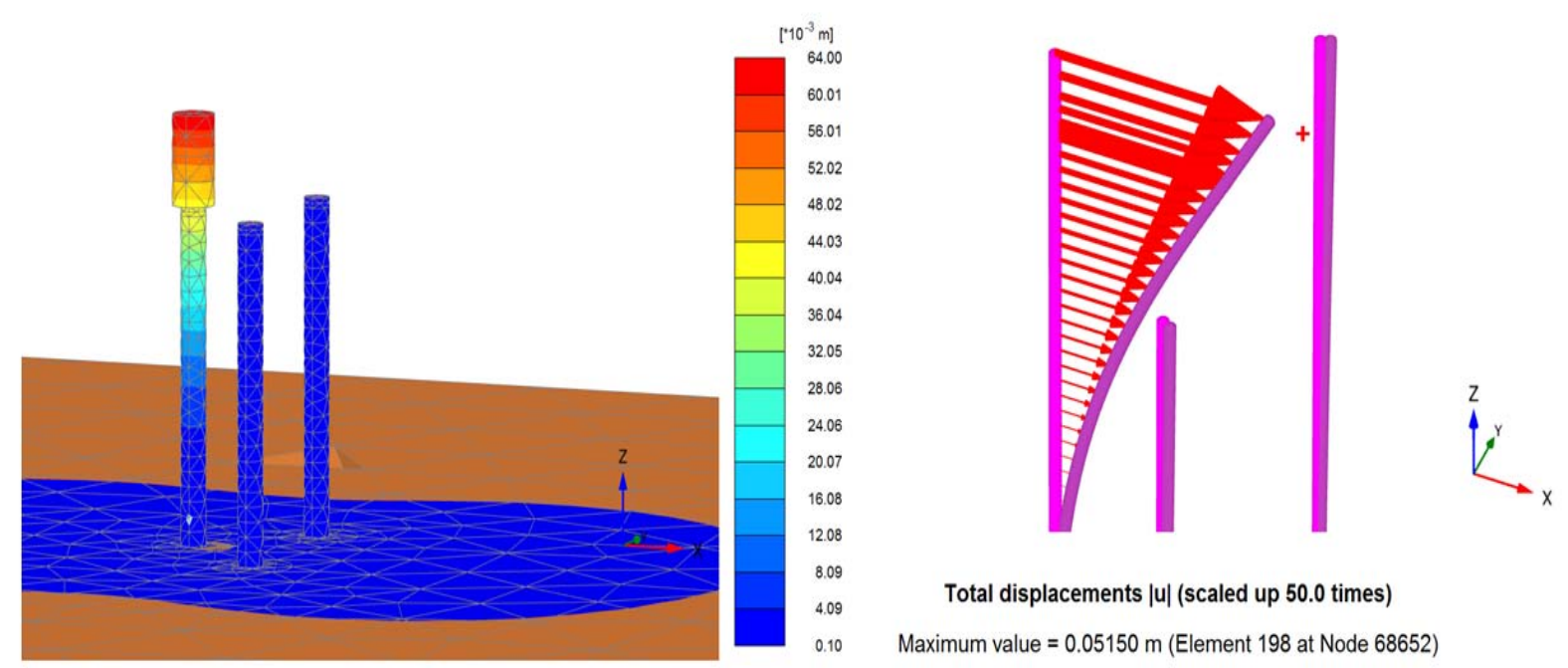

Fig. 14 - TP3 Lateral displacement - colour shadings view and vectors of lateral displacement

Table 4

Mohr - Coulomb parameters for loess - FEM calculation

\begin{tabular}{|c|c|c|c|}
\hline \multirow{3}{*}{ Test pile } & $\begin{array}{c}\text { Moisture } \\
\text { content }\end{array}$ & $\begin{array}{c}\text { Initial stiffness modulus, E } \\
{\left[\mathrm{kN} / \mathrm{m}^{2}\right]}\end{array}$ & $\begin{array}{c}\text { Linear increase of stiffness } \\
\text { modulus, } \Delta \mathrm{E} \\
{\left[\mathrm{kN} / \mathrm{m}^{2} / \mathrm{m}\right]}\end{array}$ \\
\hline \multirow{3}{*}{$\mathrm{TP}_{1}$} & Natural & 2,000 & 11,350 \\
\cline { 2 - 4 } & Saturated & 100 & 3,000 \\
\hline \multirow{2}{*}{$\mathrm{TP}_{2}$} & Natural & 3,000 & 10,000 \\
\cline { 2 - 4 } & Saturated & 100 & 2,800 \\
\hline \multirow{2}{*}{$\mathrm{TP}_{3}$} & Natural & 300 & 6,000 \\
\cline { 2 - 4 } & Saturated & 100 & 2,000 \\
\hline
\end{tabular}

Following figures present the lateral displacement profile for each load test, both under natural moisture conditions and for saturated loess. The results obtained through FEM calculation are compared with the in-situ measurements. 


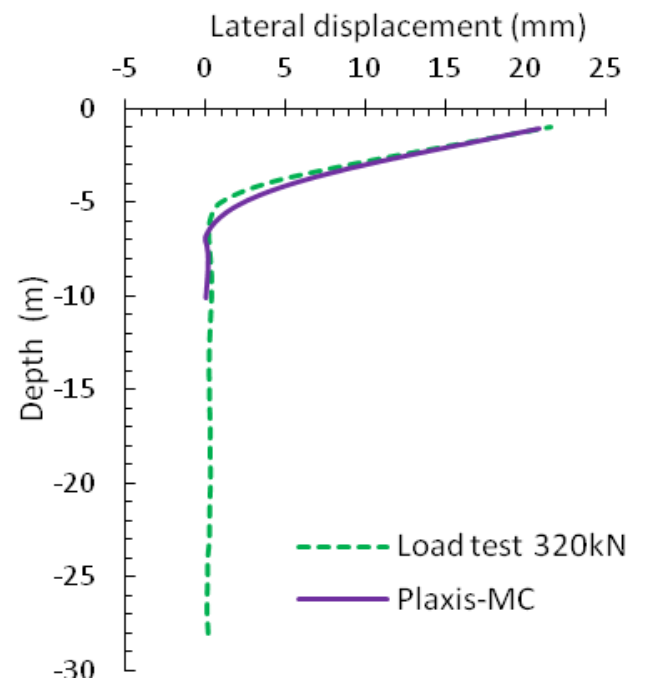

Fig. 15 - TP1 lateral displacement - dry loess

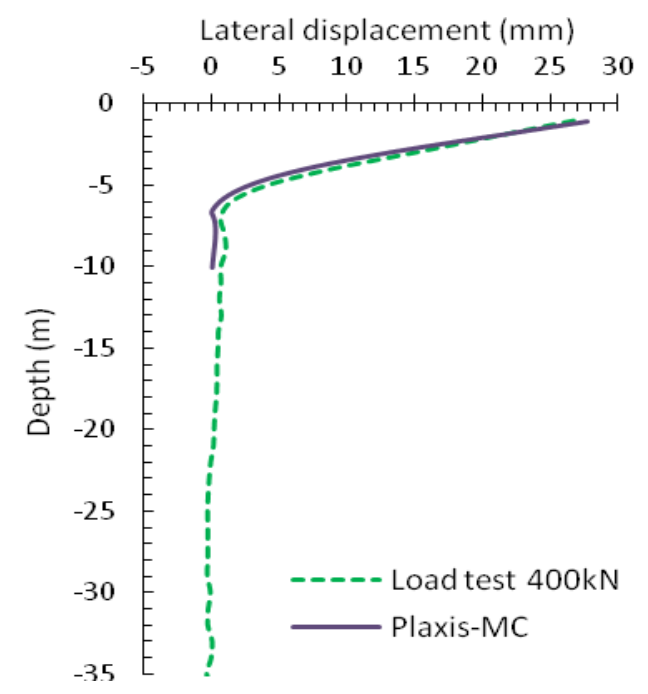

Fig. 17 - TP2 lateral displacement - dry loess

Lateral displacement $(\mathrm{mm})$

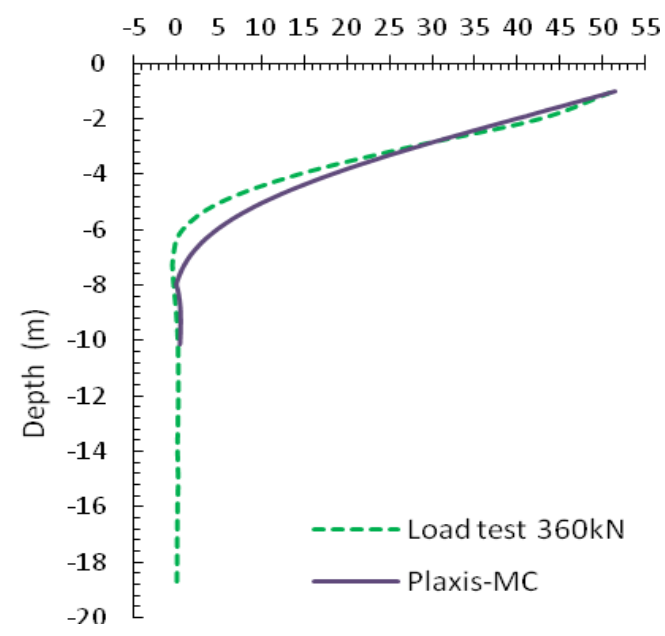

Fig. 19 - TP3 lateral displacement - dry loess

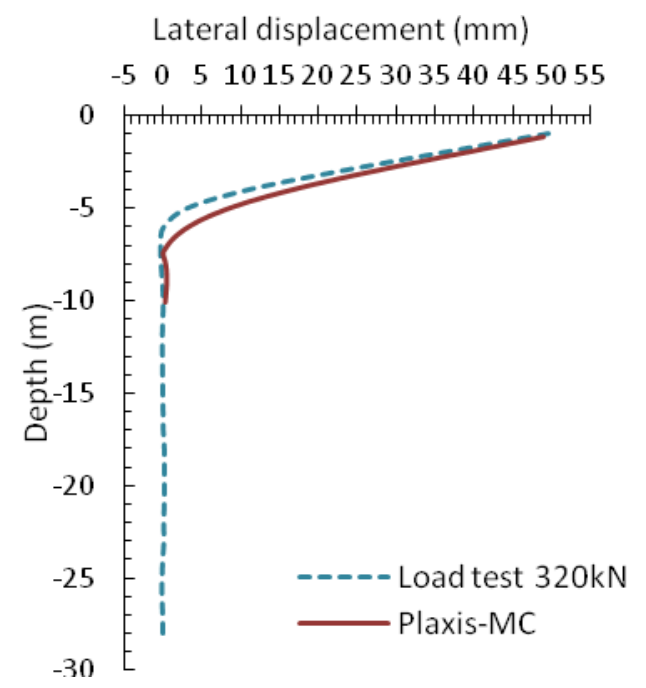

Fig. 16 - TP1 lateral displacement saturated loess

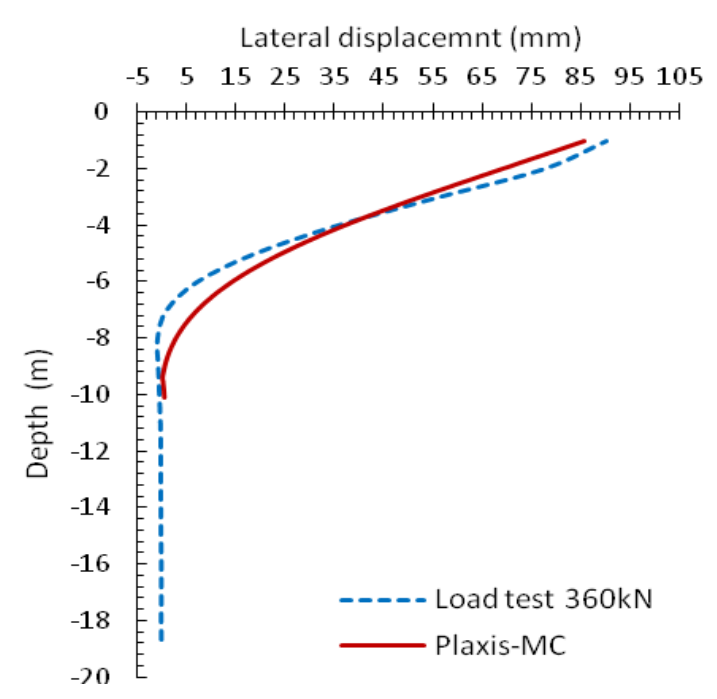

Fig. 18 - TP2 lateral displacement saturated loess

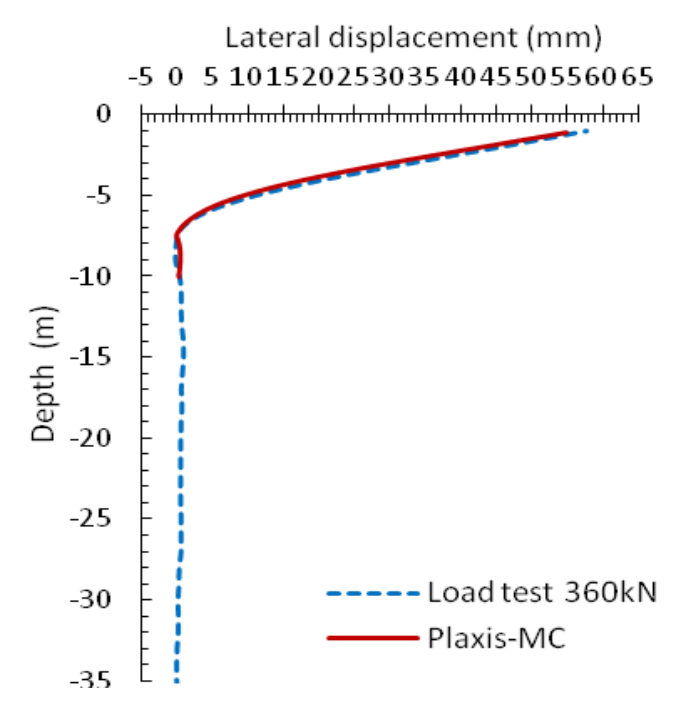

Fig. 20 - TP3 lateral displacement saturated loess 


\subsection{Interpretation of results}

A first observation in regards to the load tests results is the amplified lateral displacement of the piles in the case of saturated loess. Under the same loads applied, the displacements recorded are twice the values of those obtained for the case of loess with natural moisture content.

The stiffness and strength parameters decline abruptly when the loess is saturated, this leading to lateral displacements that clearly exceeded the elastic domain of soil behaviour.

This behaviour is a clear demonstration of how sensitive to water the loess is, transforming itself into a totally different type of soil when saturated.

The natural moisture content loess is characterized as a soil with high cohesion and angle of friction, yet the current analythical method doesn't allow for the effect of the cohesion to be acccounted for.

In regards to the results obtained through the analytical method, the subgrade reaction modulus for TP1 and TP2 has proximate values, while for TP3 this is much lower in comparison to the other two. An explanation for this would be the thickness of the layer, which in the first two cases is around $4 \mathrm{~m}$, while for the third load test the depth of loess is close to $8 \mathrm{~m}$. Also, the value of the angle of friction is lower for the third test pile, reflected into a smaller active width.

The values obtained for the soil lateral stiffness, defined through the proportionality coefficient are outside the interval suggested by NP 123:2010. For silty soils having the consistency index $I_{c}$ greater than 1 , the code suggests values between 4,000 and $6,000 \mathrm{kN} / \mathrm{m}^{4}$. The results obtained by both analytical and numerical methods for the particular test locations analyzed indicate that values over $10,000 \mathrm{kN} / \mathrm{m}^{4}$ could be considered. This high stiffness of the loessoil soils in natural state is believed to be caused by the characteristic cementation bonds between the silt particles. The results obtained could perhaps serve for a reconsideration of the suggested values for the proportionality coefficient in the case of silty soils.

The lateral displacements profile calculated using both the analytical method and numerical method are in agreement with the measured in-situ displacements, thus validating the parameters considered for calculation.

\section{Conclusions}

The results of three lateral load tests of piles in loessoil soils are compared with analytical and numerical method calculations.

The back-analysis provides a set of stiffness parameters for both natural moisture content loess and saturated loess. As the calculated lateral displacement profiles are in good agreement with the in-situ measured values, the calculations are considered to be acceptable, validating the methods adopted.

The lateral displacement profiles obtained demonstrate the decline of strength and stiffness parameters for the saturated loess, aspect which needs to be regarded in the design of any foundation element embedded into loessoil soils.

As further research areas it could be investigated the ground stiffening effect of the reaction piles located on the direction of the load, the group effect for laterally loaded piles and also the effect of axial force acting simultaneously with the lateral load. 


\section{References}

[1] Reese, C. and Van Impe, W. (2001). Single Piles and Pile Groups Under Lateral Loading. London: Taylor and Francis Group.

[2] Hetenyi, M. (1946). Beams on elastic foundations. Ann Arbor: University of Michigan Press.

[3] Terzaghi, K. (1955). Evaluations of coefficients of subgrade reaction. Geotechnique, 5 (4), pp. 297-326.

[4] Broms, B. (1964). Lateral resistance of piles in cohesive soils. Journal of Soil Mechanics and Foundation Engineering, ASCE, 90(2), pp. 27-63.

[5] Duncan, J.M. and Ooi, P.S.K. (1994). Lateral load analysis of single piles and drilled shafts. Journal of Geotechnical Engineering, ASCE, 120(5), pp. 1018-1033.

[6] Matlock, H. (1970). Correlations for design of laterally loaded piles. Journal of Soil Mechanics and Foundation Engineering, ASCE, 86(5), pp. 63-91.

[7] Monitorul Oficial ar României. (2010). Normativ privind proiectarea geotehnică a fundațiilor NP123:2010. Bucharest.

[8] Brinkgreve, R.B.J. et al. (2013). Plaxis 3D User Guide Manual. Delft University of Technology \& Plaxis bv. Delft.

[9] Saidel Engineering SRL (2013). Static Load Test Reports for Zephyr Wind Farms. Bucharest.

[10] Nip, D.C.N. and Ng, C.W. (2005). Back analysis of laterally loaded bored piles, Proceedings of the Institution of Civil Engineers, Geotechnical Engineering Journal V. 158, pp. 63-73.

[11]Basu, D., Salgado, R. and Prezzi, M. (2008). Analysis of Laterally Loaded Piles in Multilayered Soil Deposits. Publication FHWA/IN/JTRP. Joint Transportation Research Program. doi: 10.573/1288284313454.

[12] Qin, H. (2010). Response of pile foundations due to lateral force and soil movements. Thesis for Doctor of Philosophy, Griffith University, Queensland, Australia. 